\title{
Individuals with down syndrome exhibit reduced skin thermosensitivity response during intermittent physical exercise
}

\begin{abstract}
Introduction: The Down Syndrome (DS) individuals usually present decreased aerobic capacity concomitant with reductions in peak oxygen consumption. An important aspect to maintain performance and consequently the work rate during acute physical exercise is body temperature $\left(\mathrm{T}_{\text {body }}\right)$ regulation. No study has evaluated the skin thermoeffector response as well as $\mathrm{T}_{\text {body }}$ adjustments in DS individuals during acute physical exercise.
\end{abstract}

Objective: To assess skin temperature $\left(\mathrm{T}_{\text {skin }}\right)$ adjustments in individuals with Down Syndrome (DS) during intermittent physical exercise.

Methods: Two experimental groups composed of control male individuals without DS (CON; $\mathrm{n}=6 ; 32.17 \pm 3.71$ years) and male individuals with $\mathrm{DS}(\mathrm{DS} ; \mathrm{n}=6 ; 33.0 \pm 4.2$ years), paired by body surface area (BSA) and age, were used. Two experimental sessions were carried out. In the first session anthropometric measurements and a progressive exercise test until fatigue (workload in W) were performed. In the second, voluntaries underwent a submaximal exercise protocol ( $65 \%$ of the workload attained in the first session). Heart rate (HR), systolic (SBP), diastolic (DBP) and mean (MAP) blood pressures, gastrointestinal temperature $\left(\mathrm{T}_{\mathrm{tg}}\right)$ and $\mathrm{T}_{\text {skin }}$ thermoeffector data were collected.

Results: No differences were observed between CON and DS groups in HR, SBP, DBP, MAP and $T_{\text {tgi }}$ during exercise. DBP increased over time in DS group. Related to $T_{\text {skin }}$, no differences were observed in the onset threshold (CON: $37.45 \pm 0.67{ }^{\circ} \mathrm{C}$ vs. DS: $37.19 \pm$ $0.50{ }^{\circ} \mathrm{C} ; \mathrm{p}>0.05$ ) and the DS group presented lower thermosensitivity compared to CON (CON: $4.61 \pm 3.05$ vs. DS: $1.84 \pm 1.34)$.

Conclusion: Individuals with DS exhibit reduced skin thermosensitivity response during intermittent physical exercise.

Keywords: down syndrome, thermoregulation, physical exercise, blood pressure, cardiovascular
Volume 5 Issue 5 - 2020

\author{
Paulo Henrique Gonçalves,' Leonardo \\ Mateus Teixeira de Rezende, ${ }^{2}$ Emanuel \\ Mattos Della Lucia, ${ }^{1,2}$ Tiago Ferreira Leal, ${ }^{2}$ \\ Eveline Torres Pereira, ${ }^{3}$ Raquel Duarte \\ Moreira Alves, ${ }^{2}$ Paulo Roberto dos Santos \\ Amorim,' João Carlos Bouzas Marins,' \\ Antônio José Natali, ${ }^{2}$ Thales Nicolau \\ Prímola-Gomes ${ }^{1,2}$ \\ 'Laboratory of Human Performance, Federal University of \\ Viçosa/Physical Education Department, Brazil \\ ${ }^{2}$ Laboratory of Exercise Biology, Federal University of Viçosa/ \\ Physical Education Department, Brazil \\ ${ }^{3}$ Laboratory of Psychomotor Stimulation, Federal University of \\ Viçosa/Physical Education Department, Brazil
}

\section{Correspondence: Thales Nicolau Prímola-Gomes, Department of Physical Education, Federal University of Viçosa,Av. Ph. Rolfs, s/n, Viçosa, Minas Gerais, 36570-900, Brazil, Tel+553136|254II,Email thaes.gomes@ufv.br}

Received: September 23, 2020 | Published: October 06, 2020
Abbreviations: DS, down syndrome; $\mathrm{VO}_{2 \text { peak }}$, peak oxygen consumption; $\mathrm{T}_{\text {body }}$, body temperature; $\mathrm{NO}$, nitric oxide; $\mathrm{CON}$, controlindividuals without Down; BSA, body surface area; BD, Body density; $\mathrm{W}$, workload; HR, heart rate; $\mathrm{T}_{\text {tgi }}$, gastrointestinal temperature; $\mathrm{SGU}$, specific gravity of urine; $\mathrm{T}_{\mathrm{amb}}$, temperature ambient; $\mathrm{RH}$, humidity; SBP, systolic blood pressure; DBP, diastolic blood pressure; MAP, mean arterial pressure; $\mathrm{T}_{\text {skin }}$, skin temperature; $\mathrm{T}_{\text {chest }}$, chest temperature; $\mathrm{T}_{\text {triceps }}$, triceps temperature; $\mathrm{T}_{\text {thig }}$, thig temperature; $\mathrm{T}_{\text {calf }}$ calf temperature

\section{Introduction}

Down syndrome (DS) is a genetic disorder characterized in $95 \%$ of cases by trisomy 21 , which is the extra junction of a chromosome to pair $21 .{ }^{1}$ In newborns it is considered the most common genetic disorder, with a worldwide incidence of approximately 1 to 2 cases per 1000 births. $^{2}$ The DS is associated with different degrees of cognitive impairment and several disorders, including congenital heart disease, gastrointestinal atresia, feeding difficulties, hearing loss, ophthalmic disease, thyroid disease and hip abnormalities. ${ }^{2}$

Previous studies have verified the physiological responses of DS individuals during acute physical exercise.$^{3-6}$ These individuals usually present decreased aerobic capacity concomitant with reductions in peak oxygen consumption $\left(\mathrm{VO}_{2 \text { peak }}\right) \cdot{ }^{5,7}$ Also, it has been found that $\mathrm{SD}$ is characterized by chronotropic dysfunction as showed by lower maximum heart rate values obtained during exercise than that of estimated maximum heart rate. ${ }^{5,8}$ In addition, cardiac autonomic dysfunction due to the sympathetic/parasympathetic disbalance may also occur. ${ }^{5,7-9}$ Individuals with DS exhibit a lower vagal withdrawal which in turn may lead to a predominance of parasympathetic over sympathetic tonus, resulting in chronotropic dysfunction. ${ }^{8,10}$

An important aspect to maintain performance and consequently the work rate during acute physical exercise is body temperature $\left(\mathrm{T}_{\text {body }}\right)$ regulation. This process occurs through the thermal balance between heat production and heat loss rates. ${ }^{11}$ During physical exercise there is an increase in the metabolic rate due to increased energy demand by contracting muscles, which results in heat production. For example, during intense dynamic exercise $70-80 \%$ of the energy generated will be converted into heat and will need to be dissipated. ${ }^{12,13}$ The heat dissipation pathways must be activated to avoid an excessive increase in $\mathrm{T}_{\text {body }}$. An important mechanism for heat dissipation during exercise is dry heat loss through the skin. (NEVES et al., 2015; SMITH; JOHNSON, 2016). Although several physiological aspects have been evaluated during physical exercise in DS, to the best of our knowledgement, no study has evaluated the skin thermoeffector 
response as well as $\mathrm{T}_{\text {body }}$ adjustments in $\mathrm{SD}$ individuals during acute physical exercise.

The integrated control of $\mathrm{T}_{\text {body }}$ with the cardiovascular system during acute physical exercise is an important way for the adequate management of thermal stress. ${ }^{14}$ During hyperthermia induced by submaximal acute physical exercise in compensable conditions heat dissipation needs is usually increased. ${ }^{14}$ In addition to the contracting muscles perfusion needs, the blood requirement to the skin also is increased. ${ }^{14,15}$ In a biophysical thermal exchange perspective the skin temperature $\left(\mathrm{T}_{\text {skin }}\right)$ is a result of the bidirectional heat flow between the body and the environment. ${ }^{16-18}$ Thus, acute physical exercise induced-hyperthermia (i.e. increased $\mathrm{T}_{\text {body }}$ ) will be defended by the coordinated recruitment firstly of the cutaneous vasodilation followed by sweating. ${ }^{17,18}$ The heat loss mechanism of cutaneous vasodilation, associated to increased cardiac output, becomes crucial to redirect part of the blood flow to the skin and hence substantially increase heat transfer to the peripheral circulation. ${ }^{16-18}$ Finally, it is noteworthy that a previous study showed that individuals with DS presented reduced plasma concentrations of nitric oxide (NO), which was associated with vasomotor dysfunction. ${ }^{19}$

Therefore, the present study aimed to assess the $\mathrm{T}_{\text {skin }}$ adjustments in individuals with DS during intermittent physical exercise.

\section{Materials and methods}

\section{Individuals}

The study was carried out with two experimental groups of control male individuals without Down Syndrome (CON; $n=6 ; 32.17 \pm 3.71$ years) and male individuals with Down Syndrome (DS; $\mathrm{n}=6 ; 33.0$ \pm 4.2 years). The individuals were properly matched by the body surface area (BSA) and age. The work was conducted considering the guidelines of the Helsinki Declaration for studies with human, and the project was approved by the institutional Human Research Ethics Committee (CEP/UFV; process $n^{\circ}$ CAAE 57130216.7.0000.5153). The volunteers signed the consent form for participation and, when necessary, the family members signed a consent form.

\section{Experimental sessions}

Data collection was performed in two experimental sessions.

First experimental session. The individuals arrived at the laboratory at 07:00am. After, the anthropometric characteristics were measured. The body mass and height were measured using a digital scale (Filizola ${ }^{\circledR}$ ) and a professional stadiometer (Sanny ES2020), respectively. Skinfolds were measured using a scientific plicometer $\left(\right.$ Cescorf $\left.^{\mathbb{B}}\right)$ following the 7-fold protocol (triceps, subscapular, chest, subaxillary, suprailiac, abdomen, thigh). ${ }^{20}$ Body density (BD) was calculated using the following equation: $B D=1.112-[0.00043499 x$ $\left.\left(\Sigma 7_{\text {foldes }}\right)+0.00000055 \times\left(\Sigma 7_{\text {folders }}\right)^{2}\right]-[0.0002882 \times$ (age $\left.)\right]$. Later, the fat percentage $(\% \mathrm{~F})$ was calculated using the following equation: $\% F$ $=[4.95 / B D)-4.5] \times 100$. The body mass index $\left(\mathrm{BMI}\right.$ in $\left.\mathrm{kg} / \mathrm{m}^{2}\right)$ was calculated using the following equation: body mass/height ${ }^{2}$. The BSA $\left(\mathrm{m}^{2}\right)$ was calculated using the following equation:BSA $=(0.007184) x$ $\left(X^{0.425}\right) \times\left(Y^{0.725}\right)$, where $X$ is the body mass $(\mathrm{kg})$ and $Y$ the height $(\mathrm{cm}) .{ }^{21}$

After anthropometric measurements, the volunteers underwent a progressive cycle ergometer (SCIFIT ISO 1000) exercise test until fatigue in order to determine the workload (W) to be used in the second experimental session. The protocol started with a workload of $15 \mathrm{~W}$ and was adjusted every $2 \mathrm{~min}$, as follows: $1^{\circ}$ adjustment $10 \mathrm{~W}$ increase; $2^{\circ}$ adjustment $-10 \mathrm{~W}$ decrease; $3^{\circ}$ adjustment onwards $-30 \mathrm{~W}$ increase, followed by a $10 \mathrm{~W}$ decrease. The workload reached in the last complete stage of the test was considered as the individual's maximum workload. The heart rate (HR in bpm) was recorded every minute using a cardiofrequencimeter (Polar RS800CX).

Second experimental session. Two days later, a second experimental session was carried out. All volunteers arrived at the laboratory by 07:00am. To take part in this session, all volunteers received at home two nutritional kits, one for dinner and one for breakfast, and an ingestible capsule (HT150002 CorTemp ${ }^{\circledR}$ Pill) for body core temperature measurements (gastrointestinal temperature $\mathrm{T}_{\mathrm{tgi}}$ in ${ }^{\circ} \mathrm{C}$ ). The volunteers were instructed to eat the standard dinner eleven hours before the test. The dinner consisted of instant noodles $($ Nissin $\AA-90 g)$ with grated parmesan cheese (Amália $\AA$ - 10g) and juice fruit (Tial ${ }^{\circledR}-200 \mathrm{ml}$. The dinner offered $600 \mathrm{kcal}(58.7 \%$ of carbohydrates, $8.3 \%$ of proteins and $33.0 \%$ of fat). The volunteers were guides to ingest the $\mathrm{T}_{\text {tgi }}$ capsule immediately after dinner. At this moment the properly functioning of the capsule/receptor system was tested (HT130042 CorTemp® DATA Recorder 262K wiHR). The volunteers were advised to have the standard breakfast two hours before the test; and consisted of bread (Milani ${ }^{\circledR}$ - $50 \mathrm{~g}$ ), processed cheese (Polenghi ${ }^{\circledR}$ - $60 \mathrm{~g}$ ) and chocolate flavored milk (Nescau ${ }^{\circledR}$ $200 \mathrm{~mL})$. The breakfast offered $398 \mathrm{kcal}(63.9 \%$ of carbohydrates, $12.6 \%$ of protein e $23.5 \%$ of fat).

Upon arriving at the laboratory, the volunteers were informed to go to the changing room and put on appropriate clothes (shorts, sneakers and socks). At this moment, a urine sample for specific gravity of urine (SGU) analysis was collected. The SGU was measured using a refractometer (Instrutherm Vantage 6250) and used to guarantee the euhydration status of the volunteers, considering appropriate density values below $1,020 \mathrm{~g} / \mathrm{mL}$. The temperature $\left(\mathrm{T}_{\text {amb }}\right)$ and humidity $(\mathrm{RH})$ in the experimental room was set at $21^{\circ} \mathrm{C}$ and $60 \%$, respectively. Before the beginning of the exercise protocol, the volunteers were kept at rest for $60 \mathrm{~min}$ for basal data collection. Then, a session of intermittent exercise on a cycle ergometer was performed.

The intermittent exercise session consisted of six 5-minute stages, with a $1 \mathrm{~min}$ interval between the stages. There was initially $2 \mathrm{~min}$ of warm-up, at a workload of $50 \%$ of the maximum workload achieved in the progressive exercise test. Subsequently, the volunteers performed the intermittent exercise at a workload of $65 \%$ of the maximal workload. The cycling velocity was maintained between $18-22 \mathrm{~km} / \mathrm{h}$.

During the exercise, along with the $\mathrm{T}_{\text {tgi }}$, the $\mathrm{T}_{\text {skin }}\left({ }^{\circ} \mathrm{C}\right)$ was measured using thermocouples (Model K, S-09K Instrutherm) fixed in four points: triceps, chest, thigh and calf, all on the right hand side of the body. The mean $\mathrm{T}_{\text {skin }}$ was obtained using the Ramanathan equation: $T_{\text {skin }}$ $=0.3\left(T_{\text {chest }}+T_{\text {triceps }}\right)+0.2\left(T_{\text {thig }}+T_{\text {call }}\right) .{ }^{22} \mathrm{~T}_{\text {skin }}$ thermoeffector activity was analyzed as previously described. ${ }^{22}$ Linear regression analysis was performed to determine the relationship between $T_{\text {skin }}$ and $T_{\text {tgi' }}$, and the intersection of the regression lines was used to estimate the heat loss onset threshold (i.e., $\mathrm{T}_{\mathrm{tgi}}$ at the starting of the rapid increase in $\mathrm{T}_{\text {skin }}$ ). Skin thermosensitivity for heat loss was defined as the regression slope of the five time points following the onset threshold and corresponded to the steepest part of the rising curve.

The HR was measured continuously during the intermittent exercise session. The systolic blood pressure (SBP in $\mathrm{mmHg}$ ) and 
diastolic blood pressure (DBP in $\mathrm{mmHg}$ ) were measured using a sphygmomanometer (Tycos) and a stethoscope (Wan Med) every $5 \mathrm{~min}$. The mean arterial pressure (MAP in $\mathrm{mmHg}$ ) was obtained using the following equation: $M A P=((2 x D B P)+S B P) / 3)$

\section{Statistical analysis}

The data distribution was verified using the Shapiro-Wilk test; and data are presented as mean $\pm \mathrm{SD}$. The comparisons between groups for weight, height, BSA, hydration status, $\% \mathrm{~F}$, age, $\mathrm{T}_{\mathrm{amb}}, \mathrm{RH}, \mathrm{BMI}$, skin heat loss onset threshold and thermosensitivity were performed using the Student $t$ test (parametric data) and the Mann Whitney test (nonparametric data). Two-way ANOVA of repeated measurements was also used, followed by Tukey's post-hoc test for SBP, DBP, MAP, $\mathrm{HR}, \mathrm{T}_{\text {tgi }}, \mathrm{T}_{\text {skin }}$. A linear regression analysis was performed to determine the relationship between $\mathrm{T}_{\text {skin }}$ and $\mathrm{T}_{\text {tgi }}$. The significance level adopted was $\alpha=5 \%$.

\section{Results}

Table 1 presents the results of the control parameters for both CON and DS groups. It was observed higher $\% \mathrm{~F}$ and $\mathrm{BMI}$ values in the $\mathrm{DS}$ group $(\mathrm{p}<0.05)$.

Table I Control parameters for control and Down Syndrome groups

\begin{tabular}{lllllll}
\hline Variable & CON & \multicolumn{5}{c}{ DS } \\
\hline Weight $(\mathrm{kg})$ & 69.2 & \pm & 8.8 & 76.4 & \pm & 14.5 \\
Height $(\mathrm{cm})$ & 164.5 & \pm & 9.7 & 154.9 & \pm & 5.2 \\
BSA $\left(\mathrm{m}_{2}\right)$ & 1.7 & \pm & 0.1 & 1.7 & \pm & 0.1 \\
SGU $(\mathrm{g} / \mathrm{ml})$ & 1010 & \pm & 0 & 1010 & \pm & 0 \\
\%F & 21.2 & \pm & 3 & $28.6 *$ & \pm & 2.7 \\
BMI $(\mathrm{kg} / \mathrm{m})$ & 25.5 & \pm & 1.5 & $31.7^{*}$ & \pm & 5.4 \\
Age $($ years $)$ & 32.1 & \pm & 3.7 & 33 & \pm & 4.1 \\
Tamb $\left({ }^{\circ} \mathrm{C}\right)$ & 21 & \pm & 1.1 & 22 & \pm & 0.8 \\
RH $(\%)$ & 61 & \pm & 3.1 & 60.3 & \pm & 3.8 \\
Ptest $(\mathrm{W})$ & 108.3 & \pm & 44.5 & 81.6 & \pm & 8.1 \\
P65\% (W) & 70 & \pm & 27.3 & 53.5 & \pm & 4 \\
\hline
\end{tabular}

BSA: body surface area; SGU: specific gravity of urine; \%F: fat percentage; BMI: body mass index; $\mathrm{T}_{\mathrm{amb}}$ : ambient temperature of the experimental room; $\mathrm{RH}$ : relative humidity; $\mathrm{W}_{\text {test }}:$ workload measured in progressive test; $\mathrm{W}_{65 \%}:$ workload used in the experimental session; CON: control without down syndrome; DS: down syndrome. data are presented as mean \pm SD. *: indicates difference between CON and DS groups $(P<0.05)$

Figure 1 shows the results of cardiovascular variables during intermittent physical exercise for CON and DS groups. For all variables evaluated (SBP, DBP, MAP and HR), no differences were observed in basal pre-exercise values $(\mathrm{p}>0.05)$. Over time it was observed increases in SBP (Figure 1A) between 5-20min in the CON group and between $10-20 \mathrm{~min}$ in the DS group $(\mathrm{p}<0.05)$. The DBP (Figure 1B) increased between 5- 20min in the DS group ( $<<0,05)$. Regarding the MAP (Figure 1C), increases were observed for both groups between $5-20 \mathrm{~min}(\mathrm{p}<0.05)$. There were no differences between groups during exercise for all variables ( $p>0.05)$. The HR (Figure 1D) increased in both groups during exercise $(\mathrm{p}<0.05)$.
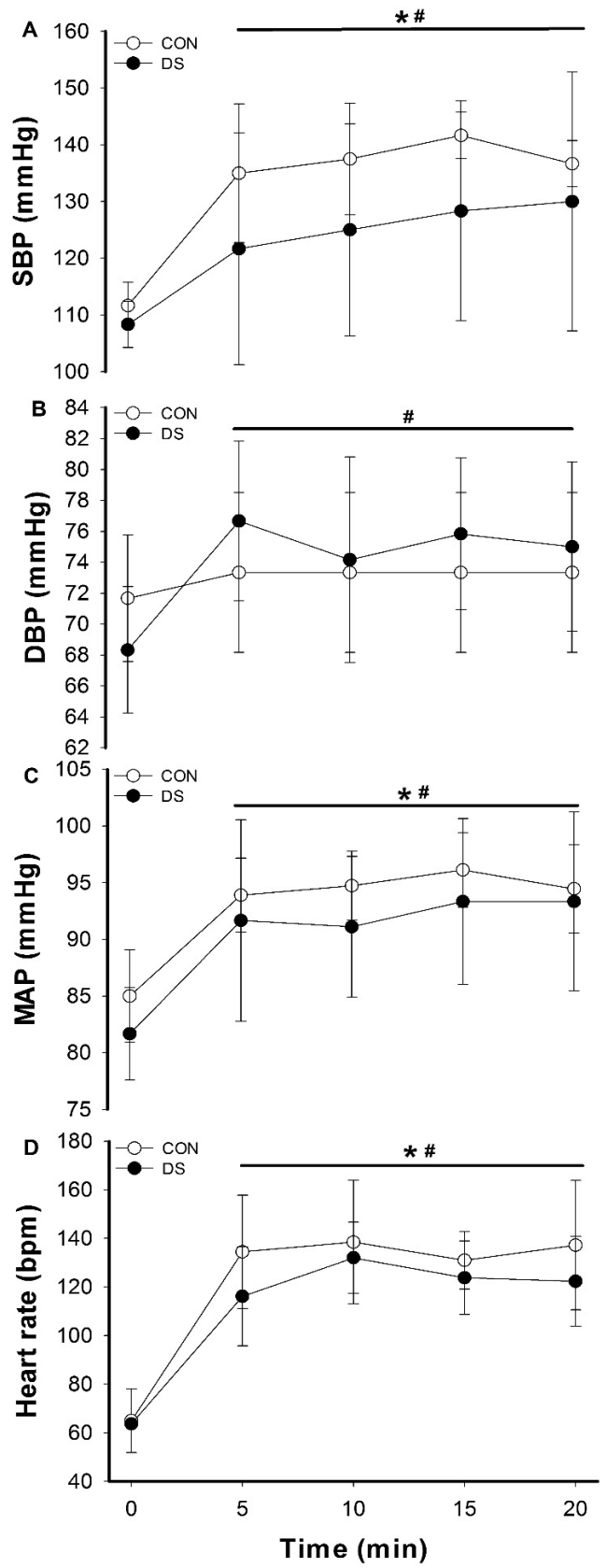

Figure I Systolic Blood Pressure (A), Diastolic Blood Pressure (C), Mean Arterial Pressure (C) and Heart Rate $(C)$ adjustments during intermittent physical exercise in individuals without Down Syndrome (CON) and with Down Syndrome (DS). Data are presented as mean \pm SD. *: differences over time for CON $(P<0.05)$; \#: differences over time for DS $(P<0.05)$.

Figure 2 exhibits the results of $\mathrm{T}_{\text {tgi }}$ (Figure 2A) and $\mathrm{T}_{\text {skin }}$ (Figure 2B) during intermittent physical exercise in CON and DS groups. It was observed increases in $\mathrm{T}_{\text {tgi }}$ during exercise in both groups, in which CON group showed increased after 10min onwards, while DS group presented increased $\mathrm{T}_{\text {tgi }}$ after $14 \mathrm{~min}(\mathrm{p}<0.05)$. However, there was no difference between groups $\left(\mathrm{CON}: 37.46 \pm 0.25{ }^{\circ} \mathrm{C}\right.$ vs. DS: $\left.37.24 \pm 0.16^{\circ} \mathrm{C} ; \mathrm{p}>0.05\right)$. Related to $\mathrm{T}_{\text {skin }}$, there was an increase during exercise over time in the CON group from $9 \mathrm{~min}$ on $(\mathrm{p}<0.05)$. 


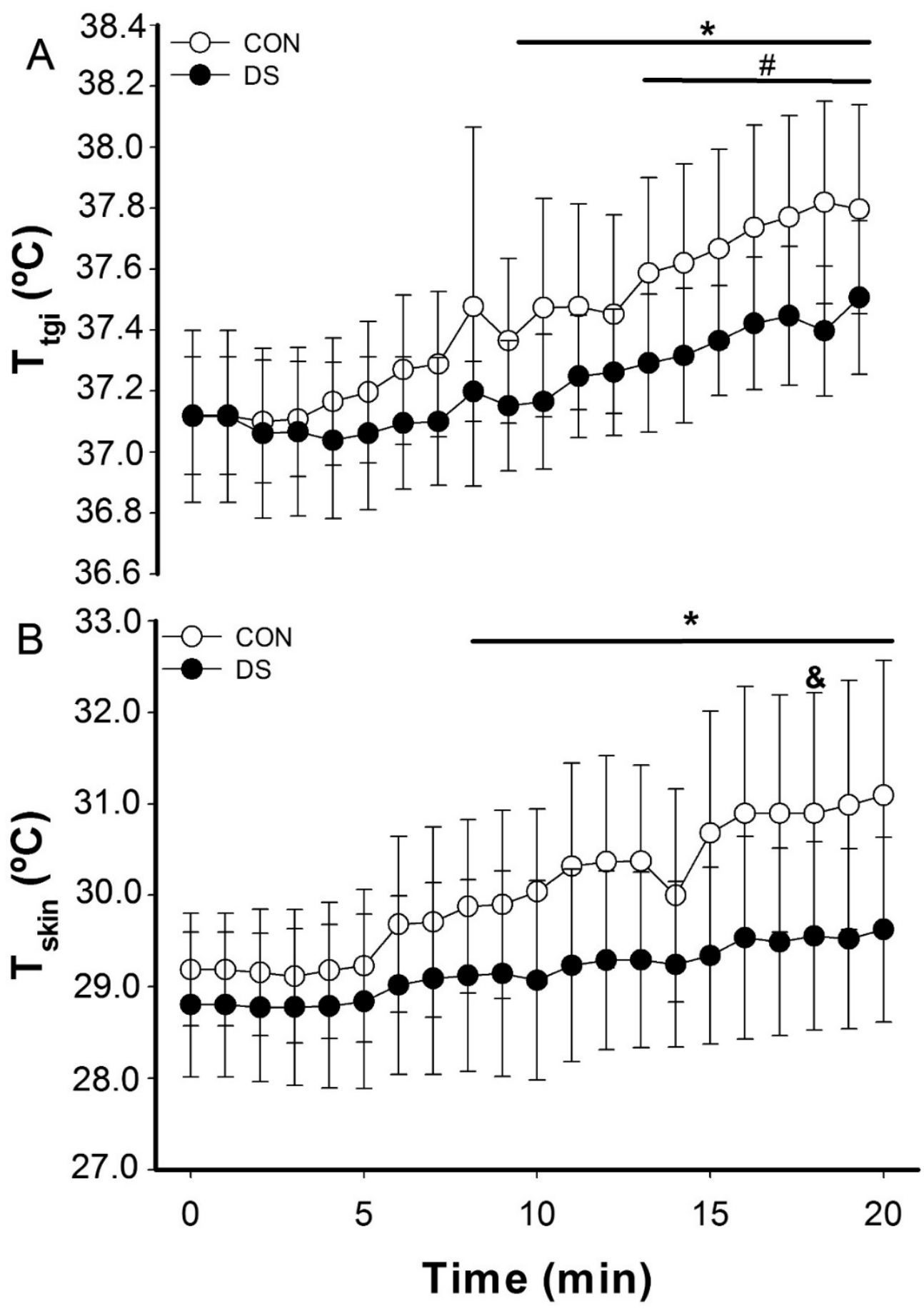

Figure 2 (A) Body temperature $\left(T_{\text {tgi }}\right)$ and $(B)$ skin temperature $\left(T_{\text {skin }}\right)$ adjustments during intermittent physical exercise in individuals without Down Syndrome $(C O N)$ and with Down Syndrome (DS). Data are presented as mean \pm SD. *: differences over time for CON $(P<0.05)$; \#: differences over time for DS $(P<$ 0.05);\&: CON vs. DS $(P<0.05)$.

Figure 3 shows the skin onset threshold for heat loss (Figure $3 \mathrm{~A}$ ), the skin thermosensitivity (Figure $3 \mathrm{~B}$ ) and the linear regression between $\mathrm{T}_{\text {skin }}$ and $\mathrm{T}_{\mathrm{tgi}}$ (Fig.3C). No differences were observed in the onset threshold (CON: $37.45 \pm 0.67{ }^{\circ} \mathrm{C}$ vs. DS: $37.19 \pm 0.50{ }^{\circ} \mathrm{C}$; $\mathrm{p}>0.05$ ). More important, DS group had lower thermosensitivity compared to CON (CON: $4.61 \pm 3.05$ vs. DS: $1.84 \pm 1.34$ ). Both groups showed a positive relationship between $\mathrm{T}_{\text {skin }}$ and $\mathrm{T}_{\mathrm{tgi}}(\mathrm{CON}$ : $\mathrm{R}^{2}=0.97$ vs. DS: $\left.\mathrm{R}^{2}=0.95\right)$, however, the CON group presented a stronger relationship. 

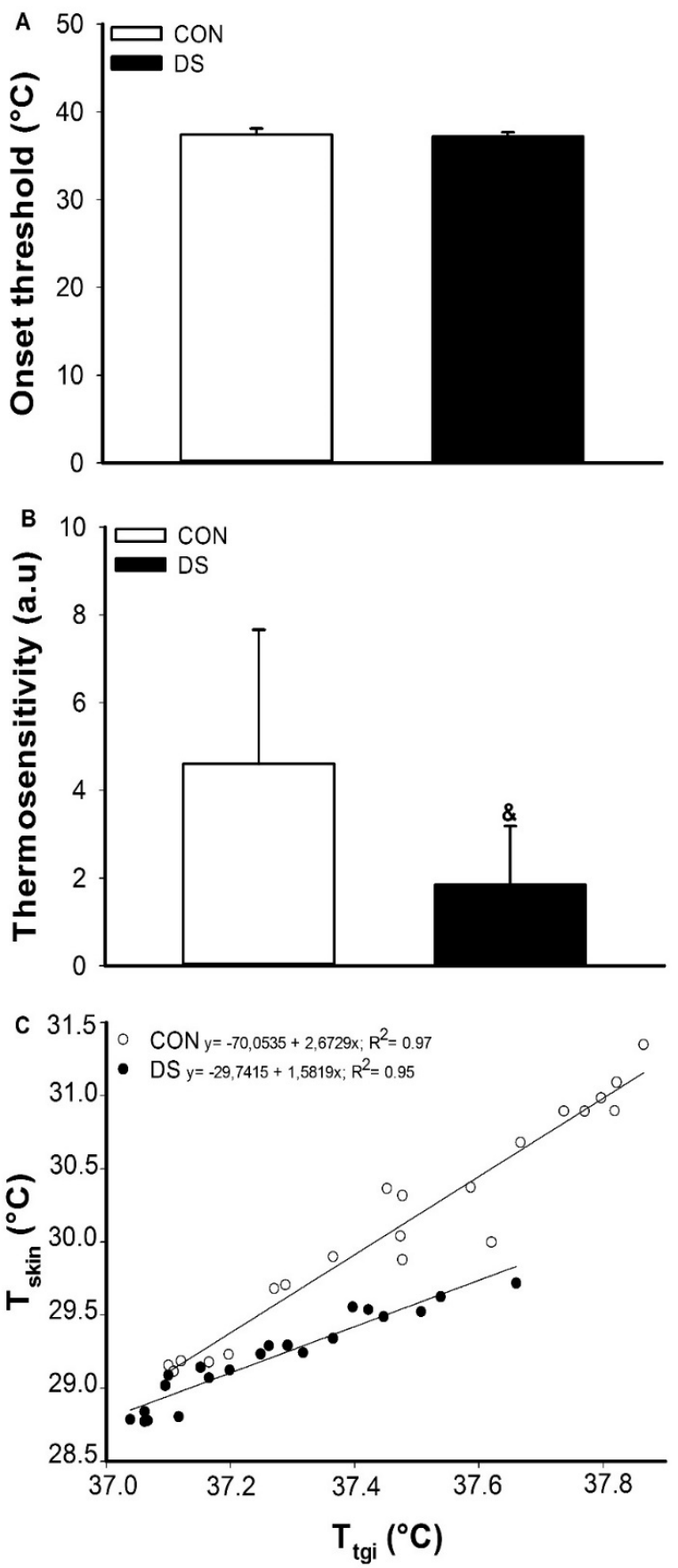

Figure $3 \mathrm{~T}_{\text {ski }}$ thermoeffector analysis during intermittent physical exercise in individuals without Down Syndrome (CON) and with Down Syndrome (DS). A: Onset threshold for heat loss; B: Thermosensitivity; C: Linear regression between $\mathrm{T}_{\text {skin }}$ and $\mathrm{T}_{\text {tgi }}(C)$. Data are presented as mean \pm SD. \&: CON vs. DS $(P<0.05)$.

\section{Discussion}

The present study aimed to assess the $T_{\text {skin }}$ thermoeffector adjustments in individuals with DS during intermittent physical exercise. Our main result points to the deregulation of the skin thermosensitivity in DS during the intermittent exercise protocol applied.
During intermittent exercise protocols like that used in the present study, increases in $\mathrm{T}_{\text {body }}$ are usually expected. ${ }^{23-25} \mathrm{It}$ is well established in the literature that $\mathrm{T}_{\text {body }}$ rises as a momentary imbalance provoked by the greater rates of heat production related to heat loss. ${ }^{26}$ Some factors may contribute to such inequality. In exercising humans heat production rising occurs due to the increase in metabolism to supply the energy demands, mainly that on the exercise contraction-related muscles sites..$^{27}$ Depending on the exercise modality, heat content is a thermal challenge to the homeostasis and needs to be managed properly to prevent unwelcome events as, for example, hyperthermiarelated fatigue. ${ }^{15}$ Thus, approximately $70-80 \%$ of the energy produced must be dissipated as heat. ${ }^{28}$ Therefore, achieve the heat balance is the purpose of body heat regulation.

As previously described, the components of heat balance, i.e., metabolic heat production, heat loss and $\mathrm{T}_{\text {body }}$ present dynamic and steady-state phases during intermittent exercise. ${ }^{29}$ The exercise protocol applied here was designed short enough to study only the dynamic phase and in order to assess the thermoeffector activity. ${ }^{30}$ During the intermittent exercise and in an autonomic perspective, metabolic heat production (not measured in the present study) increases followed by increases in heat loss and finally in $\mathrm{T}_{\text {body }}{ }^{29} \mathrm{In}$ association, cardiovascular adjustments are required to sustain adequate blood perfusion for the whole body tissues, especially the contracting muscles. ${ }^{26,27}$ As found in the present study, the thermoregulatory and cardiovascular adjustments observed in the CON group did not occur at the same extent in the DS group.

Our main purpose was to assess the $\mathrm{T}_{\text {skin }}$ adjustments in individuals with DS during intermittent physical exercise. Usually, under the thermoregulatory point of view thermoeffector activity has been assessed by analyzing both the central command-associated component, i.e., the onset threshold (beginning of skin heat loss in our case) and the end-organ effector-associated component, i.e., the thermosensitivity (slope of the relationship between $\mathrm{T}_{\text {skin }}$ and $\mathrm{T}_{\text {body }}$ in our case). ${ }^{30}$

Our main result showed that the skin thermosensitivity was decreased in the DS group during the intermittent exercise protocol applied. Moreover, although we did not find differences between groups, the $\mathrm{T}_{\text {skin }}$ did not increase during exercise in the DS group. Together with these results, it was observed an increase in DPB during exercise in the DS group. To the best of our knowledgement, this is the first study to measure $\mathrm{T}_{\text {body }}$ and $\mathrm{T}_{\text {skin }}$ during exercise in individuals with DS. Thus, what factors associated with the heat dissipation process through the skin could be altered in the DS group to explain the differences observed in thermosensitivity?

In conditions of increased $\mathrm{T}_{\text {body }}$ like that adopted in the present study the blood flow to the skin displays a high capacity of variation, from approximately $250-300 \mathrm{~mL} / \mathrm{min}$ under normothermic resting conditions to 6-7 L/min during heat challenges. ${ }^{31}$ The control of the skin circulation during hyperthermia is associated to autonomic and reflex control mechanisms. ${ }^{32}$ Autonomic mechanisms include active vasodilation by a non-adrenergic pathway and passive dilation by reductions in vasoconstrictor nerve activity. ${ }^{32} \mathrm{On}$ the other hand, there are reflex control mechanisms of cutaneous vasodilation..$^{33}$ Previous studies have shown that $\mathrm{NO}$ has critical in increasing skin blood flow through cutaneous active vasodilation..$^{34,35}$ Thus, NO participation can partially explain the decreased thermosensitivity found in the DS group, since decreased plasma levels of NO associated with 
vasomotor dysfunction has been previously demonstrated in these individuals. ${ }^{19,36}$

Furthermore, an unusual increase in DBP was observed in the DS group during intermittent exercise. It is well established the role of increased skin blood flow and vascular conductance during exerciseinduced hyperthermia to match the heat loss demands. ${ }^{33}$ Therefore, the decrease in the thermosensitivity of DS individuals observed in the present study may also be associated with an increase in DBP during exercise. Indeed, previous studies have shown that DS individuals may have elevated peripheral vascular resistance ${ }^{7}$ and reduced peripheral vasodilator response. ${ }^{37}$

\section{Conclusion}

In conclusion, our results indicate that individuals with DS exhibit reduced skin thermosensitivity response during intermittent physical exercise.

\section{Funding}

This study was supported in part by CNPq (Conselho Nacional de Desenvolvimento Científico e Tecnológico), CAPES (Coordenação de Aperfeiçoamento de Pessoal de Nível Superior) and FAPEMIG (Fundação de Amparo à Pesquisa do Estado de Minas Gerais).AJ Natali is a CNPq fellow.

\section{Acknowledgments}

None.

\section{Conflicts of interest}

No potential conflict of interest relevant to this article was reported.

\section{References}

1. Epstein CJ. Down syndrome. Abnormal states of brain and mind. In: Springer, edn. Boston.1989.

2. Ni She R, Filan PM. Trisomy 21--incidence and outcomes in the first year, in Ireland today. Ir Med J. 2014;107(8):248-249.

3. Prasher VP. Down syndrome and thyroid disorders: a review. Downs Syndr Res Pract. 1999;6(1):25-42.

4. Vis JC, Duffels MG, Winter MM, et al. Down syndrome: a cardiovascular perspective. J Intellect Disabil Res. 2009;53(5):419-425.

5. Baynard T, Pitetti KH, Guerra M, et al. Heart rate variability at rest and during exercise in persons with down syndrome. Archives of Physical Medicine and Rehabilitation. 2004;85(8):1285-1290.

6. Mendonca GV, Pereira FD, Fernhall B. Heart rate recovery and variability following combined aerobic and resistance exercise training in adults with and without Down syndrome. Res Dev Disabil. 2013;34(1):353-361.

7. Fernhall B, Mendonca GV, Baynard T. Reduced work capacity in individuals with Down syndrome: a consequence of autonomic dysfunction?. Exerc Sport Sci Rev. 2013;41(3):138-147.

8. Guerra M, Llorens N, Fernhall B. Chronotropic incompetence in persons with down syndrome. Arch Phys Med Rehabil. 2003;84(11):1604-1608.

9. Agiovlasitis S, Baynard T, Pitetti KH, et al. Heart rate complexity in response to upright tilt in persons with Down syndrome. Res Dev Disabil. 2011;32(6):2102-2107.

10. Figueroa A, Collier SR, Baynard T, et al. Impaired vagal modulation of heart rate in individuals with Down syndrome. Clin Auton Res. $2005 ; 15(1): 45-50$.
11. Fernhall B, Otterstetter M. Attenuated responses to sympathoexcitation in individuals with Down syndrome. J Appl Physiol (1985). 2003;94(6):21582165 .

12. Gordon CJ. Temperature regulation in laboratory rodents. United Kingdom; 1993.

13. González-Alonso J, Quistorff B, Krustrup P, et al. Heat production in human skeletal muscle at the onset of intense dynamic exercise. The Journal of Physiology. 2004;524(2):603-615.

14. Vinkers CH, Penning R, Hellhammer J, et al. The effect of stress on core and peripheral body temperature in humans. Stress. 2013;16(5):520-530.

15. Wendt D, van Loon LJ, Lichtenbelt WD. Thermoregulation during exercise in the heat: strategies for maintaining health and performance. Sports Med. 2007;37(8):669-682.

16. Romanovsky AA. Skin temperature: its role in thermoregulation. Acta Physiolgica. 2014;210(3):498-507.

17. Charkoudian N. Skin blood flow in adult human thermoregulation: how it works, when it does not, and why. Mayo Clin Proc. 2003;78(5):603-612.

18. Taylor NA, Tipton MJ, Kenny GP. Considerations for the measurement of core, skin and mean body temperatures. $J$ Therm Biol. 2014;46:72-101.

19. Coppus AM, Fekkes D, Verhoeven WM, et al. Plasma levels of nitric oxide related amino acids in demented subjects with Down syndrome are related to neopterin concentrations. Amino Acids. 2010;38(3):923-928.

20. Jackson AS, Pollock ML. Generalized equations for predicting body density of men. Br J Nutr. 1978;40(3):497-504.

21. Du Bois D, Du Bois EF. A formula to estimate the approximate surface area if height and weight be known. 1916. Nutrition. 1989;5(5):303-311.

22. Ramanathan NL. A new weighting system for mean surface temperature of the human body. J Appl Physiol. 1964;19:531-533.

23. Adams WC, Fox RH, Fry AJ, et al. Thermoregulation during marathon running in cool, moderate, and hot environments. J Appl Physiol. 1975;38(6):1030-1037.

24. Rowland T, Hagenbuch S, Pober D, et al. Exercise tolerance and thermoregulatory responses during cycling in boys and men. $\mathrm{Med} \mathrm{Sci}$ Sports Exerc. 2008;40(2):282-287.

25. Mora-Rodriguez R, Del Coso J, Estevez E. Thermoregulatory responses to constant versus variable-intensity exercise in the heat. Med Sci Sports Exerc. 2008;40(11):1945-1952.

26. Rowell LB. Human cardiovascular adjustments to exercise and thermal stress. Physiol Rev. 1974;54(1):75-159.

27. Vatner SF, Pagani M. Cardiovascular adjustments to exercise: hemodynamics and mechanisms. Prog Cardiovasc Dis. 1976;19(2):91108.

28. Fisher M, Paolone V, Rosene J, et al. The effect of submaximal exercise on recovery hemodynamics and thermoregulation in men and women. Res $Q$ Exerc Sport. 1999;70(4):361-368.

29. Webb P. The physiology of heat regulation. Am J Physiol. 1995;268(4 Pt 2):R838-850.

30. Gagnon D, Kenny G. Does sex have an independent effect on thermoeffector responses during exercise in the heat?. The Journal of Physiology. 2012;590(23):5963-5973.

31. Koroxenidis GT, Shepherd JT, Marshall RJ. Cardiovascular response to acute heat stress. J Appl Physiol. 1961;16:869-872.

32. Morrison SF. Central neural control of thermoregulation and brown adipose tissue. Auton Neurosci. 2016;196:14-24. 
33. Hodges GJ, Kosiba WA, Zhao K, et al. The involvement of heating rate and vasoconstrictor nerves in the cutaneous vasodilator response to skin warming. Am J Physiol Heart Circ Physiol. 2009;296(1):H51-56.

34. Kellogg DL, Jr., Liu Y, Kosiba IF, et al. Role of nitric oxide in the vascular effects of local warming of the skin in humans. J Appl Physiol (1985). 1999;86(4):1185-1190.

35. Hodges GJ, Kosiba WA, Zhao K, et al. The involvement of norepinephrine, neuropeptide $\mathrm{Y}$, and nitric oxide in the cutaneous vasodilator response to local heating in humans. J Appl Physiol (1985). 2008;105(1):233-240.
36. Cua CL, Cooke G, Taylor M, et al. Endothelial nitric oxide synthase polymorphisms associated with abnormal nitric oxide production are not over-represented in children with Down syndrome. Congenit Heart Dis. 2006;1(4):169-174.

37. Borowski A, Zeuchner M, Schickendantz S, et al. Down syndrome as a factor influencing hemodynamic response to pulmonary artery banding. Pediatr Cardiol. 1996;17(6):375-381. 